\title{
DIFFERENT POPULATIONS OF GABAERGIC NEURONS IN THE VISUAL CORTEX AND HIPPOCAMPUS OF CAT CONTAIN SOMATOSTATIN- OR CHOLECYSTOKININ-IMMUNOREACTIVE MATERIAL ${ }^{1}$
}

\author{
PÉTER SOMOGYI,* $\ddagger \|$ ANTHONY J. HODGSON,* A. DAVID SMITH,§ M. GRACIA NUNZI, \\ ALFREDO GORIO,\| AND JANG-YEN WUף
}

* Department of Human Physiology, Centre for Neuroscience, Flinders University of South Australia, Bedford Park, South Australia, 5042; $¥ 1$ st Department of Anatomy, Semmelweis Medical School, Budapest, Hungary; \$Department of Pharmacology, Oxford University, South Parks Road, Oxford OX1 3QT, United Kingdom; || Fidia Research Laboratories, 35031 Abano Terme, Padova, Italy; and IDepartment of Physiology, The Pennsylvania State University, College of Medicine, Hershey, Pennsyluania 17033

Received February 8, 1984; Revised May 4, 1984; Accepted May 8, 1984

\begin{abstract}
The coexistence of $\gamma$-aminobutyric acid (GABA), glutamate decarboxylase (GAD), and cholecystokinin (CCK)- or somatostatin-immunoreactive material in the same neurons was studied in the hippocampus and visual cortex of the cat. One-micrometer-thick serial sections of the same neuron were reacted to reveal different antigens by the unlabeled antibody enzyme method. All CCK- and somatostatin-immunoreactive neurons in the cortex and all CCK-immunoreactive and the majority of somatostatin-immunoreactive neurons in the hippocampus that could be examined in serial sections were also immunoreactive for GABA. In neurons that were immunoreactive for GAD it was often possible to demonstrate immunoreactivity for one of the peptides as well as for GABA. GABA-immunoreactive neurons, as revealed by an antiserum to GABA, were present in all layers of the cortex and hippocampus, and their shape, size, and distribution were similar to GAD-immunoreactive neurons. All GAD-immunoreactive neurons were also positive for GABA, but the latter staining revealed additional neurons. CCK/GABA- and somatostatin/GABA-immunoreactive neurons were present mainly in layers II and upper III and in layers V and VI in the visual cortex. CCK/GABAimmunoreactive neurons were most frequently present in the strata oriens, pyramidale, and moleculare of the hippocampus and in the polymorph cell layer of the dentate gyrus. Somatostatin/GABA-immunoreactive neurons were localized mainly in the stratum oriens and in the hilus of the fascia dentata. The two peptides could not be found in the same neuron. The majority of neurons that were GABA immunoreactive did not stain for either peptide.

The presence of CCK- and somatostatin-immunoreactive material in GABAergic cortical neurons raises the possibility that neuroactive peptides affect GABAergic neurotransmission.
\end{abstract}

There is increasing evidence from structural studies that the GABAergic interneurons in the neocortex and hippocampus are a heterogeneous population with regard to their morphology and synaptic connections (see Ribak, 1978; Ribak et al., 1981;

\footnotetext{
${ }^{1}$ We are grateful to Miss Dimitra Beroukas and Mrs. Klara Boczkó for their excellent technical assistance, to Mr. D. Auger for photographic work, and to Mrs. Judy Gotch for typing the manuscript. Dr. G. J. Dockray generously supplied us with his antiserum to cholecystokinin, and the gift of an antiserum to somatostatin from Dr. J. Oliver is gratefully acknowledged. This work was supported by the Children's Medical Research Foundation of South Australia Inc., The Flinders Medical Centre Research Foundation, the Neurosurgical Research Foundation of South Australia Inc., The Epilepsy Association of South Australia Inc., and The Medical Research Council of the United Kingdom. Grants NS 13224 and EYO 3909 from the National Institutes of Health were received by J. $-\mathrm{Y}$. Wu.
}

Wolff and Chronwall, 1982; Freund et al., 1983; Hendry et al., 1983a; Somogyi et al., 1983a, 1984). Thus, one type of identified interneuron, the axoaxonic cell, which terminates exclusively on the axon initial segment of pyramidal cells, has now been shown to contain glutamate decarboxylase (GAD) (Freund et al., 1983), the enzyme synthesizing $\gamma$-aminobutyric acid (GABA).

Because the axoaxonic cell gives synapses to only the initial segment, other GAD-containing boutons which have been shown to terminate on the soma, dendrites, and spines of the postsynaptic cells (Ribak, 1978; Ribak et al., 1981; Freund et al., 1983; Hendry et al., 1983a; Somogyi et al., 1983a, d) must originate from other GABAergic neurons. Indeed there is strong indirect evidence that cortical basket cells, which give a high proportion of their synapses onto the perikarya of other neurons (Martin et al., 1983; Somogyi et al., 1983b), are also GABAergic (for discussion, see Hendry et al., 1983; Somogyi et al., 1983b). Furthermore, immunocytochemical studies on the 
distribution of GAD in cortex (Ribak, 1978; Hendrickson et al., 1981; Freund et al., 1983; Houser et al., 1983; Somogyi et al., 1983a) and hippocampus (Ribak et al., 1981; Oertel et al., 1982; Köhler and Chan-Palay, 1983a; Seress and Ribak, 1983; Somogyi et al., 1983d) show that the immunoreactive neurons differ greatly in the shape, size, and distribution of their perikarya and dendrites.

The question arises whether these differences in structural properties and synaptic connections are also accompanied by biochemical differences between the different types of GABAergic neurons. It would also be important to know whether there are differences in the molecular events when GABA exerts its action at such diverse postsynaptic sites as dendritic spines or shafts, the perikaryon, or the axon initial segment of many types of neurons.

The first indication that interneurons with smooth and sparsely spinous dendrites, which up to very recently have been thought to be GABAergic, may be heterogeneous biochemically came with the demonstration of immunoreactive material resembling several neuroactive peptides, among them somatostatin (Finley et al., 1978; Bennett-Clarke et al., 1980; Krisch, 1980; Feldman et al., 1982; Köhler and Chan-Palay, 1982b, 1983a; McDonald et al., 1982a; Shiosaka et al., 1982; Sörensen 1982; Morrison et al., 1983) and cholecystokinin (CCK) (Innis et al., 1979; Larsson and Rehfeld, 1979; Vanderhaeghen et al., 1980; Emson and Hunt, 1981; Greenwood et al., 1981; Handelmann et al., 1981; Köhler and Chan-Palay, 1982a; McDonald et al., 1982b; Hendry et al., 1983b; Peters et al., 1983) in cortical neurons morphologically very similar to those containing GAD (see above). Thus, either there are different interneuron populations, some containing GABA, others containing peptides, or alternatively some GABAergic neurons could contain more than one neuroactive substance, as do other neurons in the central and peripheral nervous system (see Lundberg and Hökfelt, 1983).

We have tested the latter hypothesis in the hippocampus and visual cortex by immunohistochemistry, reacting different sections of the same neuron for the demonstration of GABA on the one hand and for either CCK or somatostatin on the other. The hippocampus and the visual cortex were chosen because, although they have very different functions, the structure and function of GABAergic neurons have been studied most extensively in these two areas, and at least some of the organizational principles have been found to be similar.

\section{Materials and Methods}

Preparation of animals and tissue sections. Three adult cats were used. Two of the animals were anesthetized and injected with colchicine (BDH Chemicals, $6 \mu \mathrm{g} / \mu \mathrm{l}$, dissolved in artificial cerebrospinal fluid) unilaterally into the hippocampus and visual cortex as described previously (Somogyi et al., 1983d). All three animals were anesthetized 24 $\mathrm{hr}$ later with chloral hydrate $(350 \mathrm{mg} / \mathrm{kg}$, i.p.) and perfused through the heart, first with Tyrode's solution and then by a fixative containing $4 \%$ paraformaldehyde (TAAB Laboratories), $0.05 \%$ glutaraldehyde (TAAB Laboratories), $0.2 \%$ picric acid dissolved in $0.1 \mathrm{M}$ phosphate buffer, pH 7.4 (Somogyi and Takagi, 1982). After perfusion, the brain was removed from the skull and kept in the same fixative for a few hours. Slices of the hippocampus and the lateral gyrus of the cerebral cortex were dissected and washed for 1 day in several changes of $0.1 \mathrm{M}$ phosphate buffer. The tissue blocks were then dehydrated and embedded in Durcupan ACM (Fluka) resin. One-micrometer-thick serial sections were cut on an ultramicrotome and mounted on glass slides coated with egg albumin. Consecutive sections were placed on different slides, so that sections of the same cell could be incubated to reveal different antigens or used for control incubations. The sections were kept at $56^{\circ} \mathrm{C}$ overnight and then incubated for immunohistochemistry.

Antisera. Antiserum to GAD (Code No. P4,10/17) was raised in rabbits and has been characterized as described previously (Saito et al., 1974; Wu el al., 1973, 1982). This antiserum was used at a dilution of $1: 500$ in the present study.
Antiserum to CCK (Code No. L-112) was also raised in rabbits which were immunized with the C-terminal tetrapeptide of $\mathrm{CCK} /$ gastrin coupled to bovine thyroglobulin. The antiserum has been characterized and shown to be specific for the carboxyl terminus of the peptide (Dockray et al., 1981). This antiserum was used at a dilution of 1:200.

Antiserum to $\mathrm{GABA}$ was raised in rabbits as described elsewhere (A. J. Hodgson, B. Penke, A. Erdei, I. W. Chubb, and P. Somogyi, submitted for publication). The serum used in the present study (Code No. GABA7) recognizes GABA bound to a substrate through an aldehyde moiety. The application of this antiserum to the localization of GABA in the central nervous system is described in detail elsewhere (P. Somogyi, A. J. Hodgson, I. W. Chubb, B. Penke, and A. Erdei, submitted for publication). This antiserum was used at a dilution of 1:2000 in the present study.

Antiserum to somatostatin (Code No. 2L-13) was produced in rabbits by Brenda Davies and John Oliver. Synthetic somatostatin (Ayerst Research Laboratories, Montreal, Canada) was conjugated to bovine thyroglobulin and used as an immunogen. The antiserum was characterized by radioimmunoassay for somatostatin against a large number of synthetic peptides. This, and the use of serum for immunohistochemical localization of somatostatin immunoreactivity, has been described previously. (Costa et al., 1980; Buckerfield et al., 1981). This antiserum was used at a dilution of 1:100.

Immunohistochemical procedure. The unlabeled antibody enzyme procedure was used (Sternberger et al., 1970). The resin was etched using ethanolic sodium hydroxide (Lane and Europa, 1965), followed consecutively by three washes in ethanol, phosphate-buffered saline (PBS), $\mathrm{pH} \mathrm{4,} \mathrm{and} \mathrm{PBS,} \mathrm{pH} \mathrm{7.4.} \mathrm{Thereafter,} \mathrm{the} \mathrm{sections} \mathrm{were} \mathrm{incubated}$ in a humid chamber at room temperature in the following sequence: 30 min in $20 \%$ normal sheep serum; rinse in Tris $(10 \mathrm{mM})$-phosphate (10 $\mathrm{mM}$ )-buffered isotonic saline (TPBS), $\mathrm{pH} 7.4 ; 2 \mathrm{hr}$ in primary antiserum to either $\mathrm{GAD}, \mathrm{GABA}$, somatostatin, or CCK, three 20-min washes in TPBS; $1 \mathrm{hr}$ in sheep anti-rabbit IgG fraction (Silenus Laboratory, Ltd., Dandenong, Australia) diluted at 1:50; three 20-min washes in TPBS; rabbit peroxidase-antiperoxidase (Bioproducts Ltd., Bruxelles, Belgium) diluted at 1:100. All sera were diluted with TPBS containing $1 \%$ heat-inactivated normal sheep serum.

Following incubation the slides were washed in $0.1 \mathrm{M}$ phosphate buffer, $\mathrm{pH} 7.4$, preincubated for $10 \mathrm{~min}$ in $0.05 \% 3,3^{\prime}$-diaminobenzidine tetrahydrochloride (Sigma Chemical Co.) dissolved in $0.05 \mathrm{M}$ Tris- $\mathrm{HCl}$

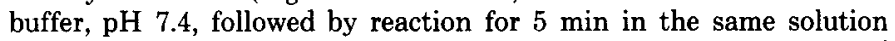
containing $0.01 \%$ hydrogen peroxide. Thereafter the slides were washed in two changes of TPBS and placed into $0.01 \% \mathrm{OsO}_{4}$ in $0.1 \mathrm{M}$ phosphate buffer for a few minutes to increase contrast. After washing in distilled water the sections were dehydrated and covered with XAM neutral mounting media.

Specificity of the immunohistochemical procedure. Method specificity was tested by omitting the $3,3^{\prime}$-diaminobenzidine from the incubation media and also by replacing the primary antiserum with nonimmune rabbit serum of the same dilution. Under these conditions no peroxidase reaction was observed in the sections.

Antiserum specificity was tested by solid phase adsorption of the diluted sera (to the peptides and to GABA) using the antigen coupled to polyacrylamide beads. A method based on that of Ternynck and Avrameas (1972) was used. Polyacrylamide beads (Biogel P200, BioRad Laboratories) were reacted with glutaraldehyde, $10 \%$, in sodium phosphate buffer, $0.1 \mathrm{M}, \mathrm{pH} 6.9$, at $56^{\circ} \mathrm{C}$ for $20 \mathrm{hr}$. The beads were washed extensively with water; then sodium phosphate buffer, $0.1 \mathrm{M}$, $\mathrm{pH} 7.7$, before a $1.0-\mathrm{ml}$ aliquot, was reacted with the antigens dissolved in the sodium phosphate buffer ( $\mathrm{pH}$ 7.7) for $20 \mathrm{hr}$ at room temperature. In each case, antigen of the highest purity available was used and, where possible, was obtained from a supplier different from the one used to prepare the immunogens. The following quantities of antigen were each reacted with $1.0 \mathrm{ml}$ of packed wet gel; GABA, $100 \mu \mathrm{mol}$ (Serva Feinbiochemica); CCK-8, $10 \mathrm{nmol}$ (Sigma); and somatostatin, $100 \mathrm{nmol}$ (Sigma). Excess aldehyde groups were blocked by incubation with $1 \mathrm{M}$ ethanolamine, $\mathrm{pH} 7.7$, for $120 \mathrm{~min}$. Beads coupled with antigen were then washed extensively with TPBS before equilibration with TPBS containing 1\% normal sheep serum. Equal quantities of gel beads and diluted antiserum were then incubated by rotation at $4^{\circ} \mathrm{C}$ for 16 to $18 \mathrm{hr}$. Antisera were diluted as follows: anti-GABA 7, 1/1000; anti-CCK, 1/100; antisomatostatin, 1/50, so that after mixing with beads the sera were at, or above, their working strength. Antisera were separated from the beads by centrifugation $\left(5000\right.$ to $\left.8000 \times g_{\mathrm{av}} \cdot \min \right)$ before application to the tissue sections. 
Because the primary aim of the present study was to demonstrate the coexistence of two or more substances in the same neuron, the above solid-phase adsorption test of each serum was carried out against all of the antigens being localized with the exception of GAD. Consecutive sections from a series were incubated, usually in the following sequence: antisera to CCK preincubated with somatostatin; antisera to CCK preincubated with GABA; antisera to CCK preincubated with CCK; antiserum to CCK; antisera to GABA preincubated with CCK antisera GABA preincubated with GABA; antisera to GABA; antisera to somatostatin; antisera to somatostatin preincubated with somatostatin; antisera to GABA preincubated with somatostatin; antisera to somatostatin preincubated with GABA; antisera to somatostatin preincubated with CCK. A sequence of slides was also used for the demonstration of GAD, GABA, and one of the peptides in the same neurons, but in this case no cross-adsorption was included because purified GAD was not available.

\section{Results}

Appearance of immunoreactivity and the effect of colchicine. Immunoreactive neurons appear dark brown in the $1-\mu \mathrm{m}$-thick sections. To increase the density of the reaction endproduct, osmium tetroxide intensification was used; this gives the sections a pale brown background and makes the nonimmunoreactive neurons recognizable (Figs. 2 and 3, and Figs. 5 to 7 ). The sections incubated in antiserum from which the specific antibodies had been removed by solid-phase adsorption were always very pale and difficult to photograph (Figs. 2, $E$ and $F$, and $5, B$ and $E$ ).

The immunostaining for GABA was strong in neuronal cell bodies including the nucleus (Figs. $2, A$ to $C, 3, A$ and $B, 5, D$ and $F, 6, A$ and $B$, and $7 C$ ). The nucleolus was always spared by the reaction endproduct (Figs. $2 A, 5 F$, and $6 B$ ). In addition, the neuropil showed small immunoreactive dots often surrounding neuronal perikarya and probably representing immunoreactive nerve terminals (Figs. 2, $B$ and $C$, and $6 B$ ). The immunostaining was very similar in the colchicine-treated and in the normal brain areas.

Immunostaining of neuronal cell bodies for CCK and somatostatin was restricted mostly to the cytoplasm (Figs. $2, D$ and $G, 3 C, 5, A, C$, and $G$, and $7 B$ ), but in strongly immunoreactive neurons the nucleus could also be slightly stained (Fig. $6 C)$. Small immunoreactive dots were also observed in the sections reacted for peptides, but they were much fewer than in the sections reacted for GABA. In the sections from the normal cat, peptide-immunoreactive perikarya were very rare and only weakly stained. Colchicine injection greatly increased both the number of immunoreactive neurons and the intensity of the staining. There was a difference in the staining for the two peptides. Immunoreactivity for CCK was much stronger in both the visual cortex and the hippocampus and homogeneously filled the cytoplasm. Somatostatin-immunoreactive neurons were often stained only in small patches resembling the position of the Golgi apparatus in the perikarya. Immunostaining of neuronal perikarya for GAD was also weak in the nontreated animal. Colchicine treatment increased the intensity of the staining, but it was still usually weaker than with the other antisera.

Specificity of the immunostaining. Under our incubation conditions all peroxidase reaction endproduct was due to immunostaining.

The staining of neurons with antisera to GABA, CCK, or somatostatin was completely abolished when the antiserum was preincubated with the homologous antigen bound to polyacrylamide beads. This was also true at the level of single cells. When a cell that was known to contain the antigen, from the reaction in a consecutive section, was tested (Figs. $2, E$ and $F$, and $5, B$ and $E$ ), the reaction was completely abolished by preadsorption of the test antiserum by homologous antigen. The peptides used for the adsorption were of a different make from those used for immunization. Several batches of GABA were used in the adsorption controls. Preincubation of the antiserum to $\mathrm{CCK}$ with GABA or with somatostatin did not affect the immunostaining (Figs. $2 G$ and $5 A$ ). Similarly, preincubation of the antiserum to GABA with $\mathrm{CCK}$ or with somatostatin did not affect the immunostaining (Figs. $2 C$ and $5 D$ ). Finally, preincubation of the antiserum to somatostatin with GABA or with CCK did not affect the immunostaining.

The adsorption tests show that the different antisera reveal different antigenic determinants in the cells, but the identity of the molecular species responsible for the staining cannot be determined. Therefore, all staining will be referred to as immunoreactivity resembling the antigen used for immunization.

Distribution of GABA-immunoreactive neurons in the visual cortex. A coronal section of the lateral gyrus is illustrated in Figure 1. Immunoreactive neurons were present in all layers and, in addition, scattered neurons were found in the white matter. The delineation of the layers was difficult in the specimens; therefore, only the border of layer I was indicated in Figure 1. There was no obvious pattern in the distribution of neurons in the tangential direction. Layers II and III contained the highest density of GABA-immunoreactive neurons, and their number decreased toward the deeper layers (Fig. 1). The shape and size of the immunoreactive neurons varied greatly both within and between the layers, but on the basis of the stained perikarya their types could not be determined.

Presence of immunoreactive peptides in GABAergic neurons of the visual cortex. Incubating serial sections of the same neuron for different antigens revealed that some GABA-immunoreactive neurons also contained CCK- (Fig. 2, $D$ and $G$ ) and somatostatin-immunoreactive (Fig. $3 \mathrm{C}$ ) material. All peptide-immunoreactive neurons studied so far in the visual cortex were found to contain GABA immunoreactivity as well. Neurons could not be stained for both peptides, although immunoreactive neurons for CCK or somatostatin show a similar laminar distribution. The distribution and relative abundance of the neurons which were immunoreactive for both a peptide and GABA are shown in Figure 1. Most of them were situated in layer II and upper layer III. Scattered neurons were found in layers IV and V, and they again became more numerous in layer VI. Somatostatin-immunoreactive neurons were also frequently present in the white matter. Under our incubation conditions somatostatin-immunoreactive neurons were much more numerous than neurons immunoreactive for $\mathrm{CCK}$. Because the demonstration of peptides in most perikarya depended on colchicine treatment, no attempt was made to count the immunoreactive neurons.

The immunoreactive peptides were found most frequently in small round or elliptical GABA-containing neurons with sizes around 8 to $12 \mu \mathrm{m}$. Fusiform CCK-immunoreactive neurons were also observed with their long axis oriented perpendicular to the pia. The GABAergic neurons which contained somatostatin-immunoreactive material in the white matter were also spindle shaped with their long axis parallel to the course of the fibers.

Distribution of GABA-immunoreactive neurons in the hippocampus. All layers of the hippocampus and the dentate gyrus were found to contain GABAergic neurons (Fig. 4). The stratum radiatum contained fewer neurons than the stratum oriens and stratum moleculare of the hippocampus (Figs. 4 and $6 A$ ). The sizes and shapes of the neurons varied considerably. Small neurons were most frequently present in the stratum pyramidale, stratum moleculare, and immediately below and above the granule cell layer of the dentate gyrus. Large GABA-immunoreactive neurons were most common in the stratum oriens, the alveus, the white matter leading to the fimbria, and the hilus of the dentate gyrus. The proportion of GABA-immunoreactive neurons was similar in the colchicine-injected and in the untreated animals. 


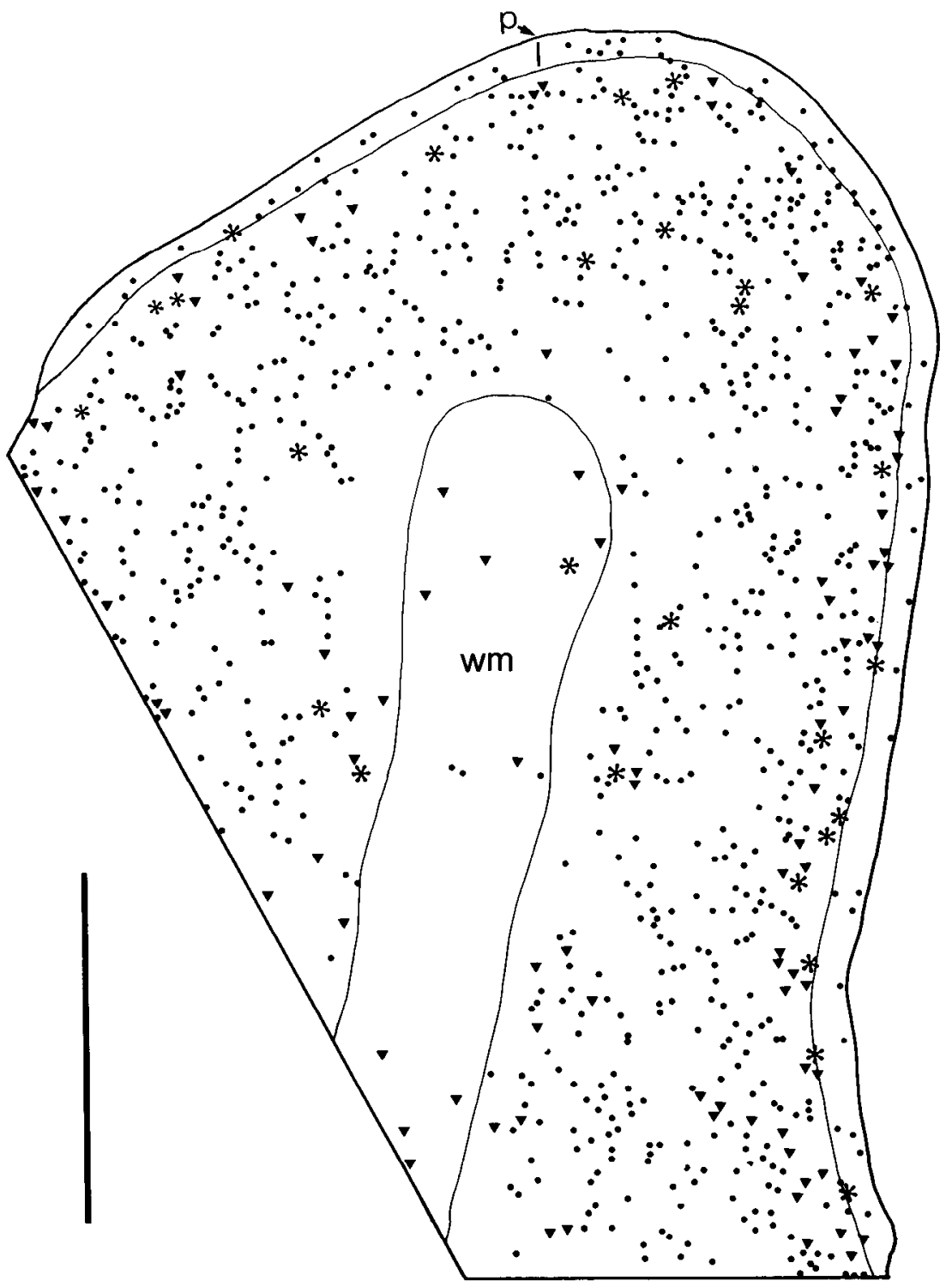

Figure 1. Camera lucida tracing of a 1- $\mu \mathrm{m}$-thick section of the striate cortex in the lateral gyrus of the cat. Dorsal is to the top and medial is to the right. Neurons immunoreactive for GABA only (dots), those immunoreactive for both CCK and GABA (asterisks), and those immunoreactive for both somatostatin and GABA (triangles) are indicated. The neurons represented by dots and triangles are each from a single section. The neurons represented by asterisks were pooled from a representative sample of 10 serial sections to illustrate their intracortical distribution. I, layer I; $p$, pia; $w m$, white matter. Scale $=1 \mathrm{~mm}$

Presence of immunoreactive peptides in GABAergic neurons of the hippocampus. CCK immunoreactivity could be demonstrated in some GABA-containing neurons most frequently in and immediately below the pyramidal cell layer, in the stratum moleculare, and in the polymorph cell layer below the granule cells in the dentate gyrus (Figs. 4 to 6). Occasional neurons were found in the stratum oriens and stratum radiatum. All CCK-immunoreactive neurons from which serial sections could be obtained in the GABA-reacted material were also stained for GABA. The neurons were mostly small to medium size (Figs. 5, $A$ to $F$, and $6, B$ and $C$ ), but in the polymorphic cell layer some large neurons were also observed (Fig. 5, $G$ to $I$ ). Somatostatin-immunoreactive neurons were localized mainly to the lower half of stratum oriens and to the hilus of the dentate gyrus (Fig. 4). They were medium to large in size, 10 to $25 \mu \mathrm{m}$ in diameter, and frequently elongated in shape with thick dendrites originating from opposing poles of the neuron
(Fig. 7A). Most but not all of the somatostatin-immunoreactive neurons could be shown to contain GABA immunoreactivity (Fig. 7). In general, GABA immunoreactivity was weaker in these neurons than in the CCK-immunoreactive ones.

Somatostatin and CCK immunoreactivity was never observed in the same neurons.

Presence of GABA, GAD, and peptide immunoreactivity in the same neurons. All GAD-immunoreactive neurons which could be found in serial sections in the hippocampal formation and in the visual cortex were also immunoreactive for GABA. In addition, GABA immunohistochemistry revealed neurons which did not show staining with the anti-GAD serum. In general, perikaryal staining for GAD was weak; thus it is likely that some GAD-containing neurons were not detected.

In many cases GABA, GAD, and either CCK (Fig. 7, $G$ to $I$ ) or somatostatin immunoreactivity could be demonstrated in the same neuron in both the hippocampus and visual cortex. 

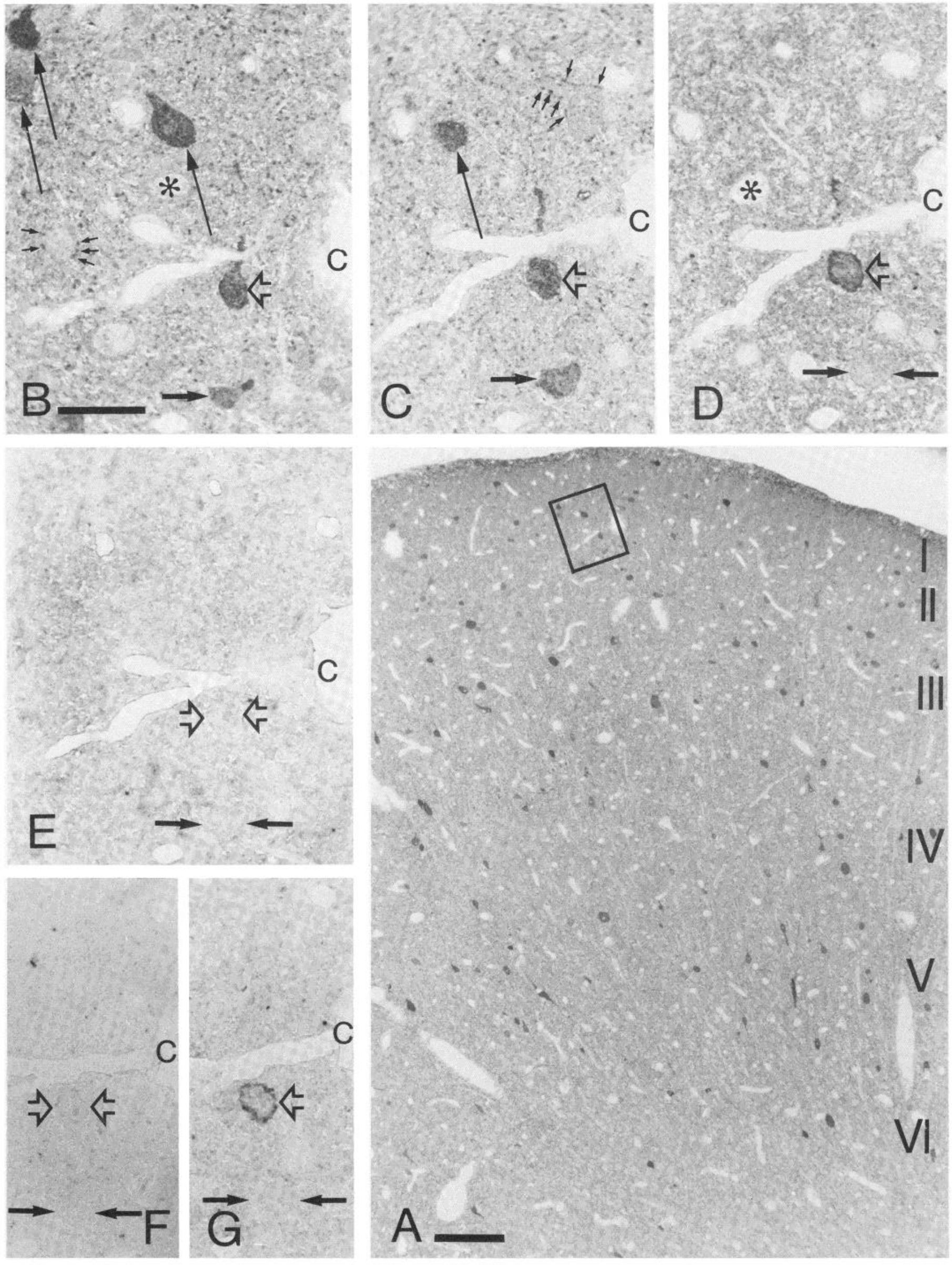

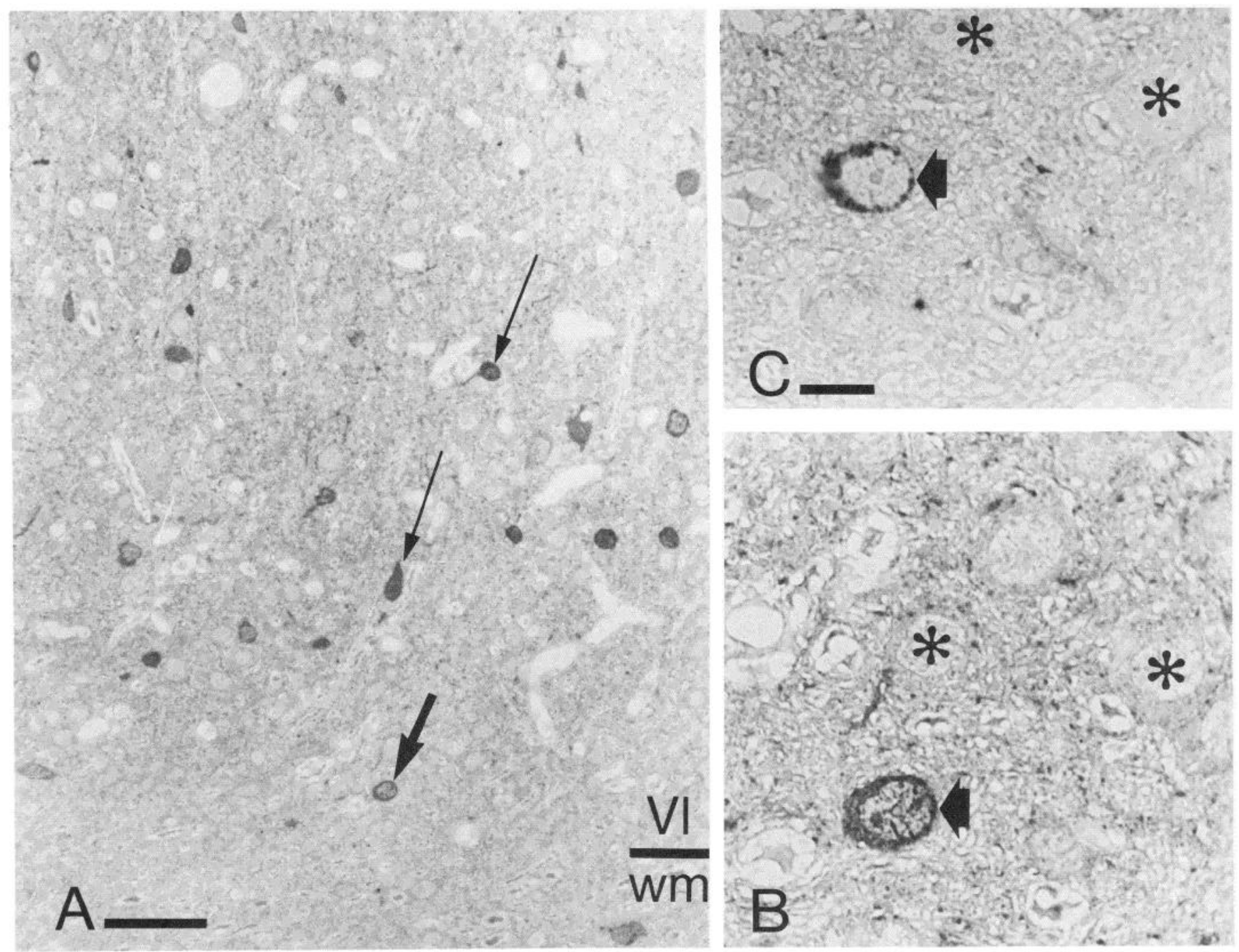

Figure 3. Coexistence of GABA and somatostatin immunoreactivity in the same cortical neuron. A, GABA-immunoreactive neurons (some indicated by long arrows) in deep layers of the striate cortex. One neuron (thick arrow) at the bottom of layer VI (VI) is shown at higher magnification in $B . B$ and $C$, Serial sections reacted to show GABA $(B)$ and somatostatin $(C)$ immunoreactivity. The same neuron is marked by the wide arrow. Neurons (asterisks) not reacting for either substance are also present. Scales: $A, 50 \mu \mathrm{m} ; B$ and $C, 10 \mu \mathrm{m}$.

\section{Discussion}

The results of the present study using postembedding immunohistochemistry are in good agreement with previous studies using other methods for the localization of GABAergic and peptide-immunoreactive neurons. GABAergic neurons have been demonstrated in the hippocampus of the rat (Ribak et al., 1978; Oertel et al., 1982; Köhler and Chan-Palay, 1983a; Seress and Ribak, 1983) and cat (Somogyi et al., 1983d) and in the neocortex of the rat (Ribak, 1978), cat (Freund et al., 1983; Somogyi et al., 1983a), and monkey (Hendrickson et al., 1981; Hendry et al., 1983b; Houser et al., 1983) using GAD immu- nohistochemistry. The antiserum raised against GABA and used in the present study stains similar neurons and in distributions similar to those that have been shown to contain GAD (Freund et al., 1983; Somogyi et al., 1983a, d) in the cat.

An antiserum to GABA was also used in a recent study for the localization of GABAergic neurons (Storm-Mathisen et al., 1983), and GABA-like immunoreactivity was reported in nonpyramidal cells in cortical areas.

The distribution of CCK- and somatostatin-immunoreactive neurons also followed the same pattern as previously shown in both hippocampus (Finley et al., 1978, 1981b; Vanderhaeghen et al., 1980; Greenwood et al., 1981; Handelmann et al., 1981;

Figure 2. Illustration of the presence of both GABA and CCK immunoreactivity in the same cortical neuron. $A$, Light micrograph of a 1- $\mu$ mthick section of area 17 in the lateral gyrus of the cortex. Darkly stained GABA-immunoreactive neuronal perikarya appear in all layers $(I$ to $V I)$. The boxed area from this section is shown at higher magnification in $B$. $B$ to $G$, Consecutive serial 1- $\mu$ m-thick sections incubated with antiserum to GABA $(B)$, with antiserum to GABA that had been preincubated with CCK coupled to polyacrylamide beads $(C)$, with antiserum to CCK $(D)$, with antiserum to GABA that had been preincubated with GABA coupled to polyacrylamide beads $(E)$, with antiserum to CCK that had been preincubated with CCK coupled to polyacrylamide beads $(F)$, and with antiserum to CCK preincubated with GABA coupled to polyacrylamide beads $(G)$. One neuron (open arrows) is immunoreactive for both GABA and CCK while another one (horizontal solid arrows) is immunoreactive for GABA only. Other GABA-immunoreactive neurons (long arrows in $B$ and $C$ ) could not be followed in all of the sections. Neurons (one indicated by the asterisk) which are not immunoreactive for either substance are also present. GABA-immunoreactive dots (small arrows), probably nerve terminals, are seen in $B$ and $C$. Capillary (c) serves as landmark. Scales: $A, 100 \mu \mathrm{m} ; B$ to $G, 20 \mu \mathrm{m}$. 


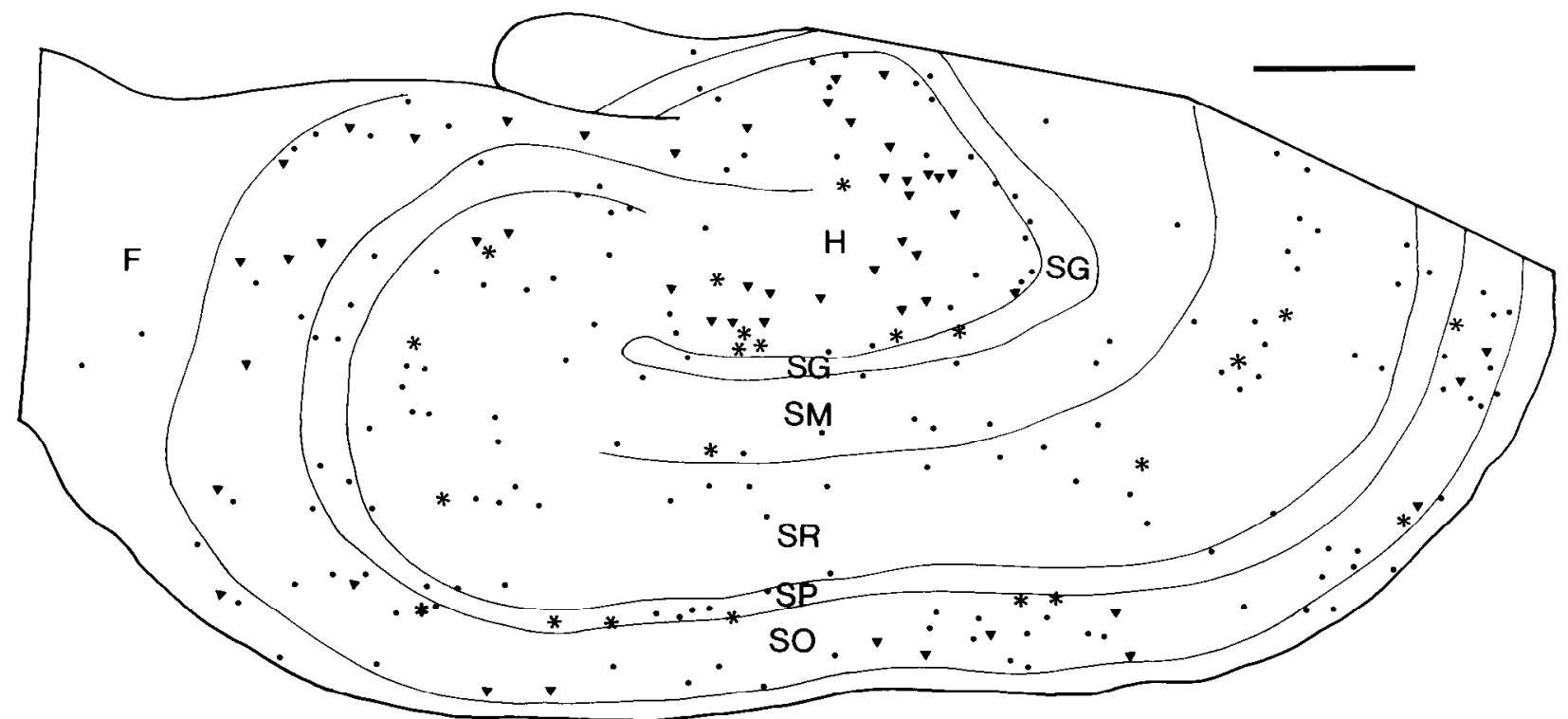

Figure 4. Camera lucida tracing of a 1- $\mu$ m-thick section of the cat hippocampus cut approximately perpendicular to its long axis. Neurons immunoreactive for GABA (dots), those immunoreactive for both GABA and CCK (asterisks), and those immunoreactive for both GABA and somatostatin (triangles) are indicated. The neurons derive from four consecutive sections, two of which were reacted to reveal GABA, one for $\mathrm{CCK}$, and one for somatostatin. $F$, fimbria; $H$, hilus, $S G$, stratum granulosum; $S M$, stratum moleculare; $S O$, stratum oriens; $S P$, stratum pyramidale; $S R$, stratum radiatum. Scale: $500 \mu \mathrm{m}$.

Feldman et al., 1982; Köhler and Chan-Palay, 1982a, b; Morrison et al., 1982) and the neocortex (Finley et al., 1978, 1981b; Innis et al., 1979, Krisch, 1980; Vanderhaeghen et al., 1980; Emson and Hunt, 1981; McDonald et al., 1982a, b; Shiosaka et al., 1982; Sörensen, 1982; Vincent et al., 1982; Hendry et al., $1983 b$; Morrsion et al., 1983; Peters et al., 1983).

Neuroactive peptides in GABAergic neurons. The main finding of the present study is that GABAergic neurons contain neuroactive peptides. The GABAergic neurons which contain either somatostatin- or CCK-immunoreactive material constitute a small proportion of all GABA-immunoreactive neurons in the cortical areas studied. Their shape and size indicate that they are probably subpopulations of nonpyramidal cells with smooth or sparsely spiny dendrites. Indeed, pre-embedding immunohistochemical studies (see above), which reveal some of the dendritic and/or axonal processes of the peptide-immunoreactive neurons, show that somatostatin and CCK immunoreactivity is present (separately) in a variety of nonpyramidal neurons known from Golgi studies. For example, on the basis of dendritic and axonal morphology, some CCK-immunoreactive neurons have been indirectly correlated with bipolar cells in the visual cortex of rat and monkey (Peters et al., 1983, Hendry et al., 1983b) and with double bouquet cells in the cat's visual cortex (Somogyi and Cowey, 1984). At present (even with the best pre-embedding immunohistochemical material) the category of nonpyramidal cell to which the peptide-immunoreactive neurons belong cannot be established. It is possible that they do not comprise a single category as delineated by synaptic connections.

Two categories of GABAergic interneurons which have been characterized in detail with respect to their synaptic connections can be excluded as candidates containing CCK or somatostatin. The axoaxonic cells of both the visual cortex (Fairén and Valverde, 1980; Somogyi et al., 1982; Freund et al., 1983) and hippocampus (Somogyi et al., 1983c, d) have such characteristic terminal axon segments that they would have been recognized in CCK or somatostatin material if they were immunoreactive. The large basket cells of the visual cortex (Martin et al., 1983; Somogyi et al., 1983b) have larger perikarya than do CCK- or somatostatin-immunoreactive neurons and they are distributed differently from the peptide-containing neurons. Both the axoaxonic cells and the large basket cells have occasional large granulated vesicles in their terminals, a finding which, in other neurons, is usually associated with peptide immunoreactivity. Thus, it is possible that some of the GABAergic neurons which were not immunoreactive for either CCK or somatostatin contain other neuroactive peptides. Indeed, vasoactive intestinal polypeptide- (Fuxe et al., 1977; for reference, see Emson and Hunt, 1981), peptide Y- (Lorén et al., 1979; Vincent et al., 1982), and enkephalin- (Finley et al., 1981a; Gall et al., 1981; Khachaturian et al., 1983) immunoreactive material have been shown to be present in nonpyramidal neurons resembling those that are immunoreactive for GAD and GABA. It remains to be established whether any of the latter peptides are in fact present in GABAergic neurons.

Molecular nature of immunoreactive material. It should be pointed out that, although we have shown the presence of CCKand somatostatin-immunoreactive material in the perikarya of GABA-containing neurons, it is not entirely clear what molecular species are present in the perikarya or are released at the terminals of the neurons. Chromatography of brain homogenates shows that besides significant amounts of triacontatriapeptide (CCK-33), dodecapeptide (CCK-12), and tetrapeptide (CCK-4), the bulk of the CCK-immunoreactive material in the brain is the octapeptide (CCK-8) (Dockray, 1976, 1980; Muller et al., 1977; Dockray et al., 1978; Rehfeld, 1978; Larsson and Rehfeld, 1979; Beinfeld, 1981). The octapeptide is also released from brain slices (Emson et al., 1980) and from cortical synaptosomes (Pignet et al., 1979) in a calcium-dependent manner. Thus, CCK-8 is a good candidate to act at the GABAergic synapses. Somatostatin is probably present in the neurons as part of a larger precursor molecule (Rorstad et al., 1979; Zyznar et al., 1979; Patel et al., 1981). This is supported by the finding in both perikarya and boutons in cortex (Lechan et al., 1983; Morrison et al., 1983) and hippocampus (Morrison et al., 1982) of immunoreactivity specific for a prosomatostatin peptide sequence which is distinct from somatostatin-14. Thus, it is not yet known which peptide segment from the prosomatostatin sequence may have relevance to GABAergic transmission. Somatostatin-immunoreactive material can also be released in 

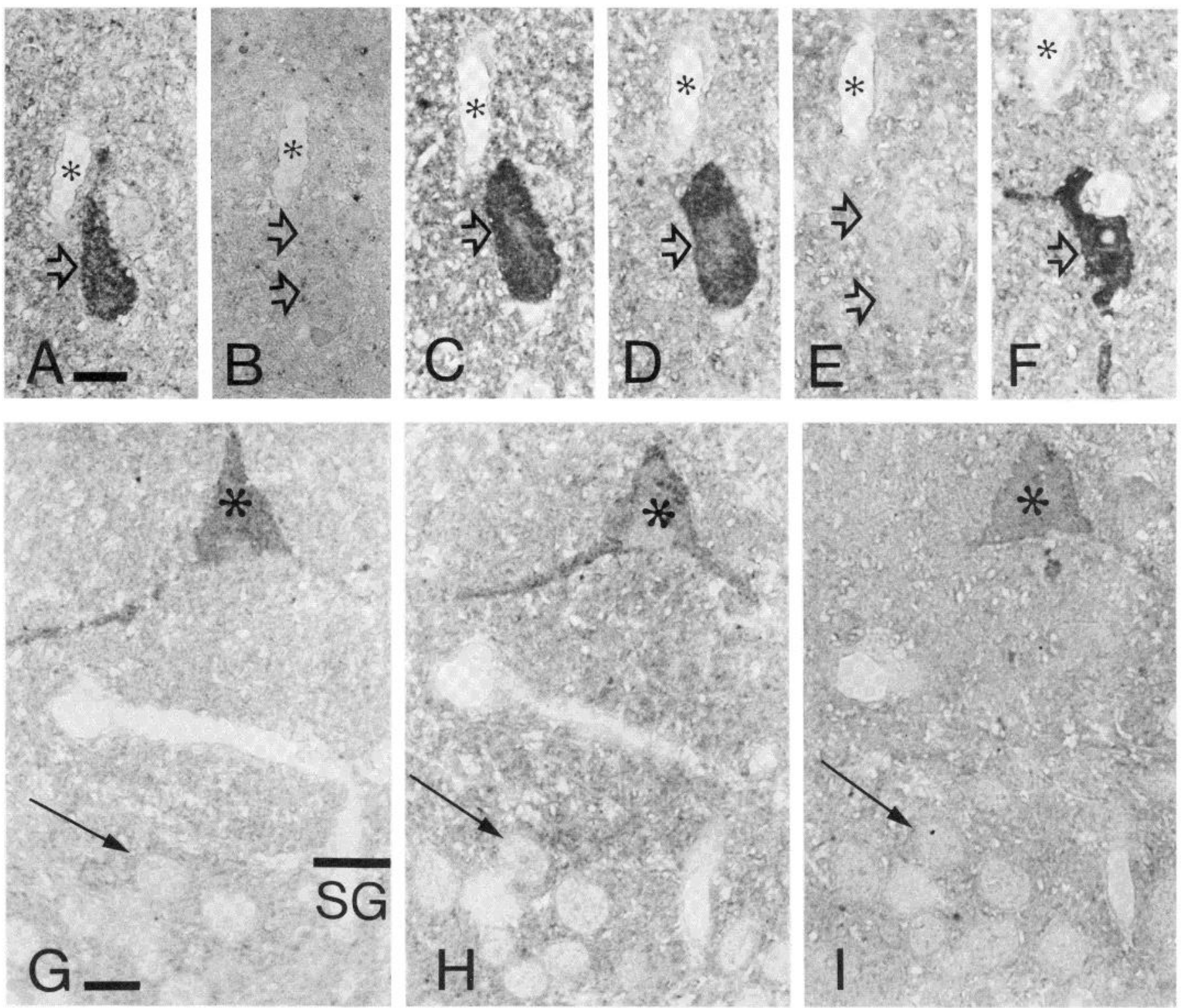

Figure 5. A to $F$, Coexistence of GABA and CCK immunoreactivity in the same neuron in the outer molecular layer of the dentate gyrus. Consecutive $1-\mu \mathrm{m}$-sections were reacted with antiserum to CCK preincubated with GABA coupled to polyacrylamide beads $(A)$; antiserum to CCK preincubated with CCK coupled to polyacrylamide beads $(B)$; antiserum to CCK $(C)$; antiserum to GABA preincubated with CCK coupled to polyacrylamide beads $(D)$; antiserum to GABA preincubated with GABA coupled to polyacrylamide beads $(E)$; and antiserum to GABA $(F)$. The same neuron (open arrows) and capillary (asterisk) are labeled. $G$ to $I$, Consecutive serial sections of the dentate gyrus. A large pyramidalshaped neuron (asterisk) in the polymorphic cell layer above stratum granulosum $(S G)$ is immunoreactive for CCK $(G)$, glutamate decarboxylase $(H)$, and GABA $(I)$. Granule cells (one marked by arrow) are not immunoreactive for any of these substances. $S c a l e s: A$ to $F, 10 \mu \mathrm{m} ; G$ to $I$, 10 $\mu \mathrm{m}$.

vitro from extrahypothalamic brain tissue including the cortex (Iversen et al., 1980; Lee and Iversen, 1981).

Possible functional implications. The use of serial sections made it possible to show that most, if not all, of the somatostatin- and CCK-immunoreactive neurons also contain GABA. The significance of this finding is 2-fold. First, it demonstrates that in addition to their differences in morphology and synaptic connectivity, cortical GABAergic neurons are also heterogeneous biochemically.

Second, the presence of neuroactive peptide-immunoreactive material in neurons which also contain an amino acid transmitter raises the possibility that the peptides and GABA are stored and could be released together at the terminals of these neurons. Indirect evidence does indicate that GABA and CCK or somatostatin might be present in the same nerve terminals.
Thus CCK immunoreactivity has been demonstrated in boutons surrounding the perikarya of pyramidal cells in the hippocampus (Larsson and Rehfeld, 1979; Greenwood et al., 1981) and also in the cortex (Köhler and Chan-Palay, 1982a; Hendry et al., 1983b; Peters et al., 1983; our unpublished observations in the cat).

Similarly, somatostatin-immunoreactive pericellular networks which could represent nerve terminals have been demonstrated in both areas (Petrusz et al., 1977; Feldman et al., 1982; Morrison et al., 1982; Köhler and Chan-Palay, 1983b). At the same time, most, if not all, boutons around the perikarya of pyramidal neurons in the visual cortex and hippocampus have been shown to contain GAD (Freund et al., 1983; Somogyi et al., 1983d); thus, it is likely that the CCK- and somatostatinimmunoreactive boutons are among the GABAergic terminals. 

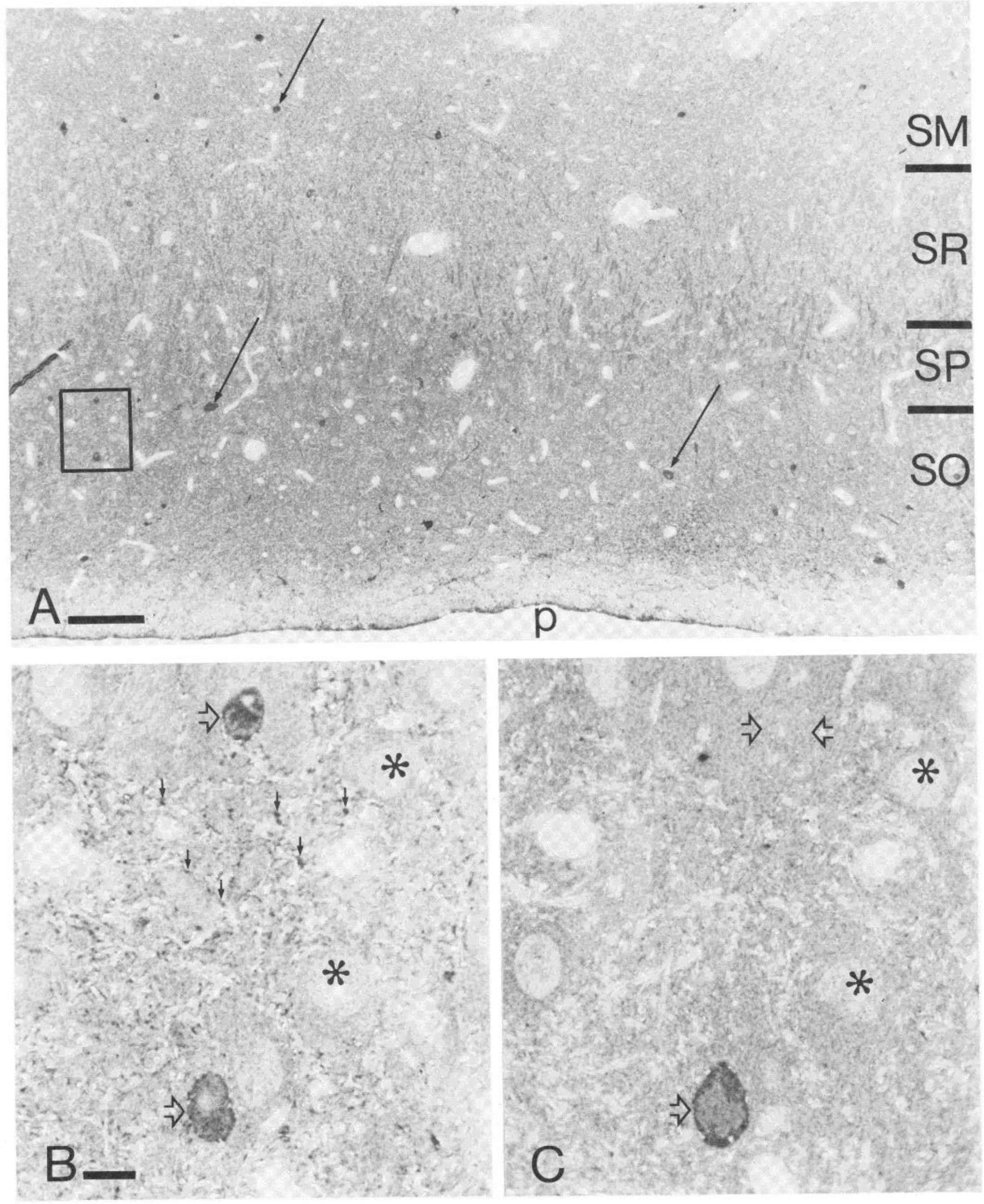

Figure 6. A, Distribution of GABA-immunoreactive neurons (some indicated by arrows) in the CA1 region of the hippocampus. The boxed area is shown at higher magnification in $B . B$, Two GABA-immunoreactive neurons (open arrows) in the pyramidal cell layer. $C$, Serial section to that shown in $B$ and incubated to show CCK immunoreactivity. The lower GABA-immunoreactive neuron in $B$ also shows CCK immunoreactivity but the upper one (two open arrows) is negative as are pyramidal cells (asterisks) in both sections. GABA-immunoreactive dots (small arrows), probably nerve terminals, are seen in $B$. p , pia; $S M$, stratum moleculare; $S O$, stratum oriens; $S P$, stratum pyramidale; $S R$, stratum radiatum. Scales: $A, 100 \mu \mathrm{m} ; B$ and $C, 10 \mu \mathrm{m}$. 

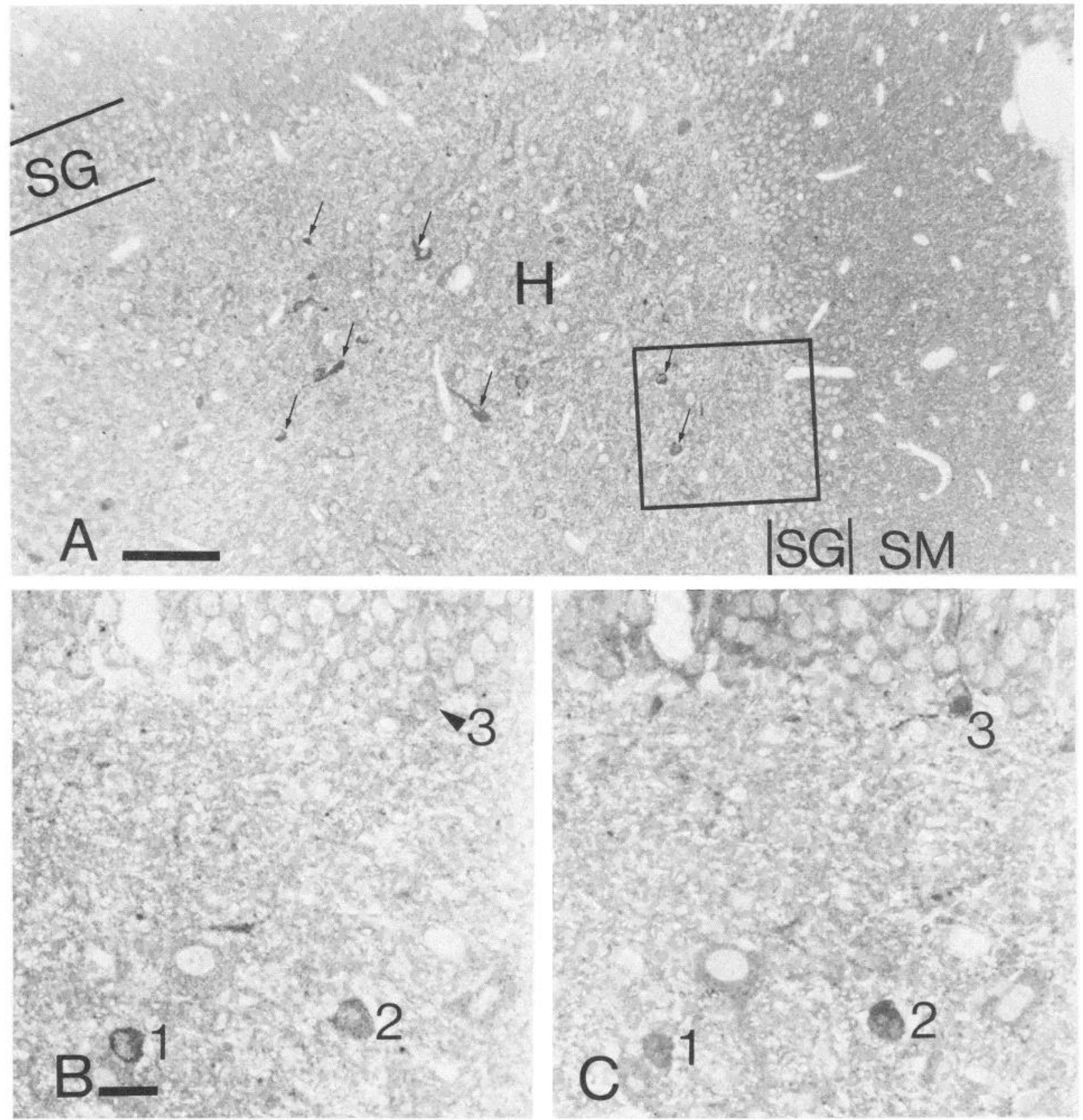

Figure 7. A, Low magnification light micrograph of the dentate gyrus reacted to show somatostatin immunoreactivity. Many neurons (arrows) in the hilus $(H)$ are immunoreactive. The boxed area from this section is shown at higher magnification in $B$. $B$, Three neurons are labeled, two of which ( 1 and 2$)$ are immunoreactive for somatostatin. $C$, The same area from a serial section was reacted for GABA and shows that all three neurons are immunoreactive. $S G$, stratum granulosum; $S M$, stratum moleculare. Scales: $A, 100 \mu \mathrm{m} ; B$ and $C, 20 \mu \mathrm{m}$.

This is further supported by the similarity of the synaptic junctions, as both CCK- (Hendry et al., 1983b) and GADimmunoreactive (Ribak, 1978) boutons form Gray's type II synaptic contacts (Gray, 1959) in the cortex. However, without double staining at the electron microscopic level, it cannot yet be excluded that the CCK-, somatostatin-, or GAD- and GABAimmunoreactive axosomatic boutons originate from two distinct neuronal populations, or that the neurons receiving them belong, in fact, to two separate populations.

Previous pre-embedding immunohistochemical studies which revealed the morphology of peptide-containing neurons in more detail indicate that the CCK- and somatostatin-immunoreactive populations are different (McDonald et al., 1982a, b; Morrison et al., 1982, 1983; Hendry et al., 1983b; Peters et al.,
1983). Furthermore, we have not been able to demonstrate the presence of the two peptides in the same neuron which, together with their different distribution in the hippocampus, implies that they play different roles in the circuitry of cortical areas. As has been mentioned earlier, different types of identified GABAergic neurons also differ in their efferent synaptic connections (for discussion, see Freund et al., 1983; Hendry et al., 1983a; Somogyi et al., 1983d). It is noteworthy that when the input from the lateral geniculate nucleus to morphologically and physiologically identified neurons in the visual cortex was studied, it was found that both pyramidal and nonpyramidal cells were activated mainly by either the fast (Y) or the slow (X) stream of afferents (Martin and Whitteridge, 1982, 1984). It is conceivable that the two streams require different local 
processing apparatus, each of which may have its unique set of GABAergic neurons containing different peptides. In any case, the question arises, why should they contain different peptides?

One possible explanation is that different parts of the postsynaptic neuron, such as the axon initial segment, the soma, and the proximal and distal dendrites which all receive GABAergic input, have different GABA receptors (see Alger and Nicoll, 1982; Bowery et al., 1983). The differences in the receptors could be brought about by the modulatory action of peptides released from the GABAergic nerve terminals and acting on binding sites related to the GABA receptor. Indeed, the receptor complex for GABA has several modulatory binding sites. Thus, separate binding sites for picrotoxin, benzodiazepines, and barbiturates are probably associated with the GABA receptor ionophore complex (see Olsen 1982; De Feudis, 1983). The endogenous substrates for these binding sites are not known; however, for the benzodiazepine receptor a polypeptide has been suggested (Guidotti et al., 1983). It would be interesting to see how somatostatin- and CCK-related peptides modify the action of GABA agonists and antagonists acting on the different binding sites associated with the GABA receptor complex.

Possible interactions at the receptors. If one assumes that $\mathrm{CCK}$ - and somatostatin-related peptides are released from the same neuron that releases GABA and they act on the same postsynaptic target, what could be their effect? GABA on its own is known to increase the conductance for chloride ions which leads to hyperpolarization and inhibition of neurons in both the neocortex and the hippocampus (Biscoe and Straughan, 1966; Krnjevic and Schwartz, 1967). With regard to the peptides, somatostatin has been shown to cause both depolarization and excitation (Dodd and Kelly, 1978) and hyperpolarization and inhibition (Pittman and Siggins, 1981) of hippocampal pyramidal cells in vitro. Inhibitory (Renaud et al., 1975; Phillis and Kirkpatrick, 1980) and excitatory (Ioffe et al., 1978; Phillis and Kirkpatrick, 1980) responses were also reported for cortical neurons, and these apparent discrepancies were recently discussed in relation to prominent depolarizing and excitatory responses observed in cortical neurons in tissue culture (Delfs and Dichter, 1983). Both CCK-8 and CCK-4 have been found to cause depolarization and excitation in the in vitro hippocampal slice preparation (Dodd and Kelly, 1981). Excitatory responses were also observed in the cortex on those neurons which responded to iontophoretically applied CCK (Ishibashi et al., 1979; Phillis and Kirkpatrick, 1980; Lamour et al., 1983). However, in the nucleus tractus solitarius (Morin et al., 1983) and in $2.8 \%$ of cortical neurons tested (Ishibashi et al., 1979), inhibitory responses to CCK-8 were also reported.

The predominantly excitatory effects observed for somatostatin and CCK in cortical structures and the inhibitory effect exerted by GABA are at first sight contradictory if these substances are stored and released by the same nerve terminals. However, as pointed out by Kelly (1982), the iontophoretic application of peptides is only a first step for the analysis of their action. The development of agonists and antagonists will be necessary to clarify the mechanisms involved. Agonists and antagonists are available for the $\mathrm{GABA}$ receptors and, assuming that the peptides and GABA interact at the postsynaptic site, the influence of the peptides could be studied both in iontophoretic studies and in in vitro binding experiments.

Coexistence of other peptides and neurotransmitters. Several peptides have now been demonstrated to be present in neurons known to contain smaller neurotransmitter molecules (see Lundberg and Hökfelt, 1983). Neurons which are throught to be GABAergic have been shown to contain motilin in the cerebellum (Chan-Palay et al., 1981), somatostatin in the reticular nucleus of the thalamus (Oertel et al., 1982, 1983), and serotonin in the dorsal raphe nucleus (Belin et al., 1981). The functional significance of these other molecules and of the ones demonstrated in the present study in relation to the action of GABA is not known. In other situations where a neuroactive peptide coexists with another transmitter, there is evidence of several kinds of mutual interaction, both pre- and postsynaptic. For example, one of the substances can modulate the release of the other; this has been shown for dopamine and CCK in the striatum (Starr, 1982; Meyer and Krauss, 1983) and cerebral cortex (Klaff et al., 1982). A different presynaptic action has been proposed for substance $P$ in the spinal cord, where it may attenuate the autoinhibition of serotonin release by serotonin (Mitchell and Fleetwood-Walker, 1981). In view of our results, it would be of interest to know whether GABA and CCK, or GABA and somatostatin, can affect each other's release from nerve terminals. The studies so far reported have not distinguished between actions on cell bodies and those on nerve endings. Thus, Robbins et al. (1982) found that GABA inhibits the spontaneous release of somatostatin-immunoreactive material from cultured neurons derived from the cortex, whereas Sheehan and De Belleroche (1983) found that CCK increased the $\mathrm{K}^{+}$-evoked release of labeled GABA from slices of the cortex. Furthermore, since there is evidence of GABA autoreceptors (see Brennan, 1982 for references), it would be worth testing whether CCK or somatostatin can influence these receptors. Interaction at the postsynaptic site has also been demonstrated for both the serotonin/substance P (Agnati et al., 1983) and the CCK/dopamine (Fuxe et al., 1981) systems.

The hippocampus and cerebral cortex, where we have shown the coexistence of GABA with CCK or somatostatin, are among the best studied brain regions not only with respect to the electrophysiological actions of these peptides but more particularly with respect to the mechanisms and functions of GABAmediated inhibition. Accordingly, these regions might profitably be explored in a search for possible subtle interactions between GABA and the two peptides that would give a functional meaning to our morphological observations.

\section{References}

Agnati, L. F., K. Fuxe, F. Benfenati, I. Zini, and T. Hökfelt (1983) The functional role of coexistence of 5-HT and substance $P$ in bulbospinal 5 -HT neurons. Substance $P$ reduces affinity and increases density of ${ }^{3} \mathrm{H}-5-\mathrm{HT}$ binding sites. Acta Physiol. Scand. 117: 299-302.

Alger, B. E., and R. A. Nicoll (1982) Pharmacological evidence for two kinds of GABA receptor on rat hippocampal pyramidal cells studied in vitro. J. Physiol. (Lond.) 328: 125-141.

Beinfeld, M. C. (1981) An HPLC and RI $\Lambda$ analysis of cholecystokinin peptides in rat brain. Neuropeptides 1: 203-209.

Belin, M. -F., D. Weisman-Nanopoulos, H. Steinbusch, A. Verhofstad, M. Maitre, M. Jouvet, and J. F. Pujol (1981) Glutamate decarboxylase and serotonin in a single neuron in the nucleus raphe dorsalis of the rat demonstrated by combined immunocytochemical staining methods. C. K. Seances Acad. Sci. (III) 293: 337-342.

Bennet-Clarke, C., M. A. Romagnano, and S. A. Joseph (1980) Distribution of somatostatin in the rat brain: Telencephalon and diencephalon. Brain Res. 188: 473-486.

Biscoe, T. J., and D. W. Straughan (1966) Micro-electrophoretic studies of neurones in the cat hippocampus. J. Physiol. (Lond.) 183: 341359.

Bowery, N. G., D. R. Hill, and A. L. Hudson (1983) Characteristics of $\mathrm{GABA}_{B}$ receptor binding sites on rat whole brain synaptic membranes. Br. J. Pharmacol. 78: 191-206.

Brennan, M. J. W. (1982) GABA autoreceptors are not coupled to benzodiazepine receptors in the rat cerebral cortex. J. Neurochem. 38: 264-266.

Buckerfield, M., J. Oliver, I. W. Chubb, and I. G. Morgan (1981) Somatostatin-like immunoreactivity in amacrine cells of the chicken retina. Neuroscience 6: 689-695.

Chan-Palay, V., G. Nilaver, S. L. Palay, M. C. Beinfeld, E. A. Zimmerman, J. -Y. Wu, and T. L. O'Donohue (1981) Chemical heterogeneity in cerebellar Purkinje cells: Existence and coexistence of glutamic 
acid decarboxylase-like and motilin-like immunoreactivities. Proc. Natl. Acad. Sci. U. S. A. 78: 7787-7791.

Costa, M., J. B. Furness, I. J. Llewellyn-Smith, B. Davies, and J. Oliver (1980) An immunohistochemical study of the projections of somatostatin-containing neurons in the guinea-pig intestine. Neuroscience 5: 841-852.

De Feudis, F. V. (1983) Commentary: Do different populations of GABA-receptors exist in the vertebrate CNS? Neurochem. Int. 5: 175-184.

Delfs, J. R., and M. A. Dichter (1983) Effects of somatostatin on mammalian cortical neurons in culture: Physiological actions and unusual response characteristics. J. Neurosci. 3: 1176-1188.

Dockray, G. J. (1976) Immunochemical evidence of cholecystokininlike peptides in brain. Nature 264: 568-570.

Dockray, G. J. (1980) Cholecystokinin in rat cerebral cortex: Identification, purification and characterization by immunochemical methods. Brain Res. 188: 155-165.

Dockray, G. J., R. A. Gregory, J. B. Hutchinson, J. I. Harris, and M. J. Runswick (1978) Isolation structure and biological activity of two cholecystokinin octapeptides from sheep brain. Nature 274: 711-713.

Dockray, G. J., R. G. Williams, and W. - Y. Zhu (1981) Development of region-specific antisera for the $\mathrm{C}$-terminal tetrapeptide of gastrin/ cholecystokinin and their use in studies of immunoreactive forms of cholecystokinin in rat brain. Neurochem. Int. 3: 281-288.

Dodd, J., and J. S. Kelly (1978) Is somatostatin an excitatory transmitter in the hippocampus? Nature 273: 674-675.

Dodd, J., and J. S. Kelly (1981) The actions of cholecystokinin and related peptides on pyramidal neurones of the mammalian hippocampus. Brain Res. 205: 337-350.

Emson, P. C., and S. P. Hunt (1981) Anatomical chemistry of the cerebral cortex. In The Organization of the Cerebral Cortex, F. O. Semitt, F. G. Worden, G. Adelman, and S. G. Dennis, eds., pp. 325345, MIT Press, Cambridge, MA.

Emson, P. C., C. M. Lee, and C. F. Rehfeld (1980) Cholecystokinin octapeptide: Vesicular localization and calcium dependent release from rat brain in vitro. Life Sci. 26: 2157-2163.

Fairén, A., and F. Valverde (1980) A specialized type of neuron in the visual cortex of cat: A Golgi and electron microscope study of chandelier cells. J. Comp. Neurol. 194: 761-779.

Feldman, S. C., C. F. Dreyfus, and E. S. Lichtenstein (1982) Somatostatin neurons in the rodent hippocampus: An in vitro and in vivo immunocytochemical study. Neurosci. Lett. 33: 29-34.

Finley, J. C. W., G. H. Grossman, P. Dimeo, and P. Petrusz (1978) Somatostatin-containing neurons in the rat brain: Widespread distribution revealed by immunocytochemistry after pretreatment with pronase. Am. J. Anat. 153: 483-488.

Finley, J. C. W., J. L. Maderdrut, and P. Petrusz (1981a) The immunocytochemical localization of enkephalin in the central nervous system of the rat. J. Comp. Neurol. 198: 511-565.

Finley, J. C. W., J. L. Maderdrut, L. G. Roger, and P. Petrusz (1981b) The immunocytochemical localization of somatostatin-containing neurons in the rat central nervous system. Neuroscience 6: 21732197.

Freund, T. F., K. A. C. Martin, A. D. Smith, and P. Somogyi (1983) Glutamate decarboxylase-immunoreactive terminals of Gogli-impregnated axo-axonic cells and of presumed basket cells in synaptic contact with pyramidal cells of the cat's visual cortex. J. Comp. Neurol. 221: 263-278.

Fuxe, K., T. Hökfelt, S. I. Said, and V. Mutt (1977) Vasoactive intestinal polypeptide and the nervous system: Immunohistochemical evidence for localization in central and peripheral neurones, particularly intracortical neurones of the cerebral cortex. Neurosci. Lett. 5: 241-246.

Fuxe, K., L. F. Agnati, C. Köhler, D. Kuonen, S. -O. Ögren, K. Andersson, and T. Hökfelt (1981) Characterization of normal and supersensitive dopamine receptors: Effects of ergot drugs and neuropeptides. J. Neural Transm. 51: 3-37.

Gall, C., N. Brecha, H. J. Karten, and K. -J. Chang (1981) Localization of enkephalin-like immunoreactivity to identified axonal and neuronal populations of the rat hippocampus. J. Comp. Neurol. 198: $335-350$.

Gray, E. G. (1959) Axo-somatic and axo-dendritic synapses of the cerebral cortex: An electron microscope study. J. Anat. 93: 420-433.

Greenwood, R. S., S. Godar, T. A. Reaves, and J. N. Hayward (1981) Cholecystokinin in hippocampal pathways. J. Comp. Neurol. 203: 335-350.
Guidotti, A., C. M. Forchetti, M. G. Corda, D. Konkel, C. D. Bennett, and E. Costa (1983) Isolation, characterization and purification to homogeneity of an endogenous polypeptide with agonistic action on benzodiazepine receptors. Proc. Natl. Acad. Sci. U. S. A. 80: 35313535 .

Handelmann, G. E., D. L. Meyer, M. C. Beinfeld, and W. H. Oertel (1981) CCK-containing terminals in the hippocampus are derived from intrinsic neurons: An immunohistochemical and radioimmunological study. Brain Res. 224: 180-184.

Hendrickson, A., S. P. Hunt, and J. -Y. Wu (1981) Immunocytochemical localisation of glutamic acid decarboxylase in monkey striate cortex. Nature 292: 605-607.

Hendry, S. H. C., C. R. Houser, E. G. Jones, and J. E. Vaughn (1983a) Synaptic organization of immunocytochemically identified GABA neurons in the monkey sensory-motor cortex. J. Neurocytol. 12:639660 .

Hendry, S. H. C., E. G. Jones, and M. C. Beinfeld (1983b) Cholecystokinin-immunoreactive neurons in rat and monkey cerebral cortex make symmetric synapses and have intimate associations with blood vessels. Proc. Natl. Acad. Sci. U. S. A. 80: 2400-2404.

Houser, C. R., S. H. C. Hendry, E. G. Jones, and J. E. Vaughn (1983) Morphological diversity of immunocytochemically identified GABA neurons in the monkey sensory-motor cortex. J. Neurocytol. 12: 617638.

Innis, R. B., F. M. A. Corrêa, G. R. Uhl, B. Schneider, and S. H. Snyder (1979). Cholecystokinin octapeptide-like immunoreactivity: Histochemical localization in rat brain. Proc. Natl. Acad. Sci. U. S. A. 76: $521-525$.

Ioffe, S., V. Havlicek, H. Friesen, and V. Chernick (1978) Effect of somatostatin (SRIF) and L-glutamate on neurons of the sensorimotor cortex in awake habituated rabbits . Brain Res. 153: 414-418.

Ishibashi, S., Y. Oomura, T. Okiyama, and S. Shibata (1979) Cholecystokinin, motilin and secretin effects on the central nervous system. Physiol. Behav. 23: 401-403.

Iversen, L. L., C. M. Lee, R. F. Gilbert, S. Hunt and P. C. Emson (1980) Regulation of neuropeptide release. Proc. R. Soc. Lond. (Biol.) 210: 91-111.

Kelly, J. S. (1982) Electrophysiology of peptides in the central nervous system. Br. Med. Bull. 38: 283-290.

Khachaturian, H., M. E. Lewis, V. Hollt, and S. J. Watson (1983) Telencephalic enkephalinergic systems in the rat brain. J. Neurosci. 3: 844-855.

Klaff, L. J., A. M. Hudson, M. Paul, and R. P. Millar (1982) A method for studying synaptosomal release of neurotransmitter candidates, as evaluated by studies on cortical cholecystokinin octapeptide release. Peptides 1: 155-161.

Köhler, C., and V. Chan-Palay (1982a) The distribution of cholecystokinin-like immunoreactive neurons and nerve terminals in the retrohippocampal region in the rat and guinea-pig. J. Comp. Neurol. 210: 136-146.

Köhler, C., and V. Chan-Palay (1982b) Somatostatin-like immunoreactive neurons in the hippocampus: An immunocytochemical study in the rat. Neurosci. Lett. 34: 259-264.

Köhler, C., and V. Chan-Palay (1983a) Gamma-aminobutyric acid interneurons in the rat hippocampal region studied by retrograde transport of glutamic acid decarboxylase antibody after in vivo injections. Anat. Embryol. (Berl.) 166: 53-66.

Köhler, C., and V. Chan-Palay (1983b) Somatostatin and vasoactive intestinal polypeptide-like immunoreactive cells and terminals in the retrohippocampal region of the rat brain. Anat. Embryol. (Berl.) 167; 151-172.

Krisch, B. (1980) Differing immunoreactivities of somatostatin in the cortex and the hypothalamus of the rat. A light and electron microscopic study. Cell Tissue Res. 212: 457-464.

Krnjević, K., and S. Schwartz (1967) The action of $\gamma$-aminobutyric acid on cortical neurones. Exp. Brain Res. 3: 320-336.

Lamour, Y., P. Dutar, and A. Jobert (1983) Effects of neuropeptides on rat cortical neurons: Laminar distribution and interaction with the effect of acetylcholine. Neuroscience 10:107-117.

Lane, B. P., and D. L. Europa (1965) Differential staining of ultrathin sections of Epon-embedded tissues for light microscopy. J. Histochem. Cytochem. 13: 579-582.

Larsson, L. -I., and J. F. Rehfeld (1979) Localization and molecular heterogeneity of cholecystokinin in the cerebral and peripheral nervous system. Brain Res. 165: 201-218.

Lechan, R. M., R. H. Goodman, M. Rosenblatt, S. Reichlin, and J. F. 
Habener (1983) Prosomatostatin-specific antigen in rat brain-Localization by immunocytochemical staining with an antiserum to a synthetic sequence of preprosomatostatin. Proc. Natl. Acad. Sci. U. S. A. $80: 2780-2784$.

Lee, C. -M., and L. L. Iversen (1981) Release of somatostatin from extra-hypothalamic rat brain slices: Inhibition by dopamine and morphine. Brain Res. 219: 355-361.

Lorén, I., J. Aluments, R. Hakanson, and F. Sundler (1979) Immunoreactive pancreatic polypeptide ( $\mathrm{PP}$ ) occurs in the central and peripheral nervous system: Preliminary immunocytochemical observations. Cell Tissue. Res. 200: 179-186.

Lundberg, J. M., and T. Hökfelt (1983) Coexistence of peptides and classical neurotransmitters. Trends Neurosci. 6: 325-333.

Martin, K. A. C., and D. Whitteridge (1982) The morphology, function and intracortical projections of neurones in area 17 of the cat which receive monosynaptic input from the lateral geniculate nucleus (LGN). J. Physiol. (Lond.) 328: 37-38P.

Martin, K. A. C., and D. Whitteridge (1984) Form, function, and intracortical projections of spiny neurones in the striate visual cortex of the cat. J. Physiol. (Lond.), in press.

Martin, K. A. C., P. Somogyi, and D. Whitteridge (1983) Physiological and morphological properties of identified basket cells in the cat's visual cortex. Exp. Brain Res. 50: 193-200.

McDonald, J. K., J. G. Parnavelas, A. N. Karamanlidis, N. Brecha, and J. I. Koenig (1982a) The morphology and distribution of peptidecontaining neurons in the adult and developing visual cortex of the rat. I. Somatostatin. J. Neurocytol. 11:809-824.

McDonald, J. K., J. G. Parnavelas, A. N. Karamanlidis, G. Rosenquist and $\mathrm{N}$. Brecha (1982b) The morphology and distribution of peptidecontaining neurons in the adult and developing visual cortex of the rat. III. Cholecystokinin. J. Neurocytol. 11: 881-895.

Meyer, D. K., and J. Krauss (1983) Dopamine modulates cholecystokinin release in neostriatum. Nature 301: 338-340.

Mitchell, R., and S. Fleetwood-Walker (1981) Substance P, but not TRH, modulates the 5-HT autoreceptor in ventral lumbar spinal cord. Eur. J. Pharmacol. 76: 119-120.

Morin, M. P., P. De Marchi, J. Champagnat, J. J. Vanderhaeghen, J. Rossier, and M. Denavit-Saubie (1983) Inhibitory effects of cholecystokinin octapeptide on neurons in the nucleus tractus solitarius. Brain Res. 265: 333-338.

Morrison, J. H., R. Benoit, P. J. Magistretti, N. Ling, and F. E. Bloom (1982) Immunohistochemical distribution of prosomatostatin-related peptides in hippocampus. Neurosci. T ett. 34: 137-142.

Morrison, J. H., R. Benoit, P. J. Magistretti, and F. E. Bloom (1983) Immunohistochemical distribution of pro-somatostatin-related peptides in cerebral cortex. Brain Res. 262: 339-343.

Muller, J. E., E. Straus, and R. S. Yalow (1977) Cholecystokinin and its COOH-terminal octapeptide in the pig brain. Proc. Natl. Acad. Sci. U. S. A. 74: 3035-3037.

Oertel, W. H., E. Mugnaini, D. E. Schmechel, M. L. Tappaz, and I. J. Kopin (1982) The immunocytochemical demonstration of gamma aminobutyric acid-ergic neurons-Methods and application. In $\mathrm{Cy}$ tochemical Methods in Neuroanatomy, V. Chan-Palay and S. L. Palay, eds., pp. 297-329, Alan R. Liss, New York.

Oertel, W. H., A. M. Graybiel, E. Mugnaini, R. P. Elde, D. E. Schmechel, and I. J. Kopin (1983) Coexistence of glutamic acid decarboxylase- and somatostatin-like immunoreactivity in neurons of the feline nucleus reticularis thalami. J. Neurosci. 3: 1322-1332.

Olsen, R. W. (1982) Drug interactions at the GABA receptor-ionophore complex. Annu. Rev. Pharmacol. Toxicol. 22: 245-277.

Patel, Y. C., T. Wheatley, and C. Ning (1981) Multiple forms of immunoreactive somatostatin: Comparison of distribution in neural and nomneural tissues and portal plasma of the rat. Endocrinology 109: $1943-1949$.

Peters, A., M. Miller, and L. M. Kimerer, (1983) Cholecystokinin-like immunoreactive neurons in rat cerebral cortex. Neuroscience 8: 431448.

Petrusz, P., M. Sar, G. H. Grossman, and J. S. Kizer (1977) Synaptic terminals with somatostatin-like immunoreactivity in the rat brain. Brain Res. 137: 181-187.

Phillis, J. W., and J. R. Kirkpatrick (1980) The actions of motilin, luteinizing hormone releasing hormone, cholecystokinin, somatostatin, vasoactive intestinal peptide, and other peptides on rat cortical neurones. Can. J. Pharmacol. 58: 612-623.

Pignet, M., E. Straus, and R. S. Yalow (1979) Release of cholecystokinin from a synaptosome-enriched fraction of rat cerebral cortex. Life
Sci 25: 339-342.

Pittman, Q. J., and G. R. Siggins (1981) Somatostatin hyperpolarizes hippocampal pyramidal cells in vitro. Brain Res. 221: 402-408.

Rehfeld, J. F. (1978) Immunochemical studies on cholecystokinin II. Distribution and molecular heterogeneity in the central nervous system and small intestine of man and hog. J. Biol. Chem. 253: 40224030.

Renaud, L. P., J. B. Martin, and P. Brazeau (1975) Depressant action of TRH, LH-RH and somatostatin on activity of central neurones. Nature 255: 233-235.

Ribak, C. E. (1978) Aspinous and sparsely-spinous stellate neurons in the visual cortex of rats contain glutamic acid decarboxylase. J. Neurocytol. 7: 461-478.

Ribak, C. E., J. E. Vaughn, and K. Saito (1978) Immunocytochemical localization of glutamic acid decarboxylase in neuronal somata following colchicine inhibition of axonal transport. Brain Res. 140: 315332.

Ribak, C. E., J. E. Vaughn, and R. P. Barber (1981) Immunocytochemical localization of GABA-ergic neurones at the electron microscopic level. Histochem. J. 13: 555-582.

Robbins, R. J., R. E. Sutton, and S. Reichlin (1982) Effects of neurotransmitters and cyclic AMP on somatostatin release from cultured cerebral cortical cells. Brain Res. 234: 377-386.

Rorstad, O. P., J. Epelbaum, P. Brazeau, and J. B. Martin (1979) Chromatographic and biological properties of immunoreactive somatostatin in hypothalamic and extrahypothalamic brain regions of the rat. Endocrinology 105: 1083-1092.

Saito, K., J. -Y. Wu, T. Matsuda, and E. Roberts (1974) Immunochemical comparison of vetebrate glutamate decarboxylase. Brain Res. 65: $277-285$.

Seress, L., and C. E. Ribak (1983) GABA-ergic cells in the dentate gyrus appear to be local circuit and projection neurons. Exp. Brain Res. 50: 173-182.

Sheehan, M. J., and J. De Belleroche (1983) Facilitation of GABA release by cholecystokinin and caerulein in rat cerebral cortex. Neuropeptides 3: 429-434.

Shiosaka, S., K. Takatsuki, M. Sakanaka, S. Inagaki, H. Takagi, E. Senba, Y. Kawai, H. Iida, H. Minagawa, V. Hara, T. Matsuzaki, and M. Tohyama (1982) Ontogeny of somatostatin-containing neuron system of the rat: Immunohistochemical analysis. II. Forebrain and diencephalon. J. Comp. Neurol. 204: 211-224.

Somogyi, P., and A. Cowey (1984) Double bouquet cells in the cerebral cortex. In Cerehral Cortex, F. F. Jones and A. Peters, eds., Vol. 1, pp. 337-360, Plenum Press, New York.

Somogyi, P., and H. Takagi (1982) A note on the use of picric acidparaformaldehyde-glutaraldehyde fixative for correlated light and electron microscopic immunocytochemistry. Neuroscience 7: 17791783.

Somogyi, P., T. F. Freund, and A. Cowey (1982) The axo-axonic interneuron in the cerebral cortex of the rat, cat and monkey. Neuroscience 7: 2577-2608.

Somogyi, P., T. F. Freund, J. -Y. Wu, and A. D. Smith (1983a) 'The section Golgi impregnation procedure. II. Immunocytochemical demonstration of glutamate decarboxylase in Golgi-impregnated neurons and in their afferent synaptic boutons in the visual cortex of the cat. Neuroscience 9: 475-480.

Somogyi, P., Z. F. Kisvárday, K. A. C. Martin, and D. Whitteridge (1983b) Synaptic connections of morphologically identified and physiologically characterized large basket cells in the striate cortex of cat. Neuroscience 10: 261-294.

Somogyi, P., M. G. Nunzi, A. Gorio, and A. D. Smith (1983c) A new type of specific interneuron in the monkey hippocampus forming synapses exclusively with the axon initial segments of pyramidal cells. Brain Res. 259: 137-142.

Somogyi, P., A. D. Smith, M. G. Nunzi, A. Gorio, H. Takagi, and J.-Y. Wu (1983d) Glutamate decarboxylase immunoreactivity in the hippocampus of the cat. Distribution of immunoreactive synaptic terminals with specific reference to the axon initial segment of pyramidal neurons. J. Neurosci., 3: 1450-1468.

Somogyi, P., T. F. Freund, and Z. F. Kisvärday (1984) Different types of ${ }^{3} \mathrm{H}$-GABA accumulating neurons in the visual cortex of rat. Characterization by combined autoradiography and Golgi impregnation. Exp. Brain Res. 54: 45-56.

Sörensen, K. V. (1982) Somatostatin: Localization and distribution in the cortex and subcortical white matter of human brain. Neuroscience $7:$ : $1227-1232$. 
Starr, M. S. (1982) Influence of peptides on ${ }^{3} \mathrm{H}$-dopamine release from superfused rat striatal slices. Neurochem. Int. 4: 233-240.

Sternberger, L. A., P. H. Hardy, Jr., J. J. Curculis, and H. G. Meyer (1970) The unlabelled antibody-enzyme method of immunohistochemistry. Preparation and properties of soluble antigen-antibody complex (horseradish peroxidase-antihorseradish peroxidase) and its use in identification of spirochetes. J. Histochem. Cytochem. 18. 315-333.

Storm-Mathisen, J., A. K. Leknes, A. T. Bore, J. L. Vaaland, P. Edminson, F. -M. S. Haug, and O. P. Ottersen (1983) First visualization of glutamate and GABA in neurons by immunocytochemistry. Nature 301: 517-520.

Ternynck, T., and S. Avrameas (1972) Polyacrylamide-protein immunoadsorbents prepared with glutaraldehyde. FEBS Lett. 23: 24-28.

Vanderhaeghen, J. J., F. Lotstra, J. Demey, and C. Gilles (1980) Immunohistochemical localization of cholecystokinin-like and gastrin-like peptides in the brain and hypophysis of the rat. Proc. Natl. Acad. Sci. U. S. A. 77: 1190-1194.

Vincent, S. R., L. Skirboll, T. Hökfelt, O. Johansson, J. Lundberg, R.
P. Elde, L. Terenius, and J. Kimmel (1982) Coexistence of somatostatin-like and avian pancreatic polypeptide (APP)-like immunoreactivity in some forebrain neurons. Neuroscience. 7: 439-446.

Wolff, J. R., and B. M. Chronwall (1982) Axosomatic synapses in the visual cortex of adult rat. A comparison between GABA-accumulating and other neurons. J. Neurocytol. 11: 409-425.

Wu, J. - Y., T. Matsuda, and E. Roberts (1973) Purification and characterization of glutamate decarboxylase from mouse brain. J. Biol. Chem. 248: 3029-3034.

Wu, J. -Y., C. T. Lin, C. Brandon, T. S. Chan, H. Mohler, and J. G. Richards (1982) Regulation and immunocytochemical characterization of glutamic acid decarboxylase. In Cytochemical Methods in Neuroanatomy, V. Chan-Palay and S. L. Palay, eds., pp. 279-296, Alan R. Liss, Inc., New York.

Zyznar, E. S., J. M. Conlon, V. Schusdziarra, and R. H. Unger (1979) Properties of somatostatin-like immunoreactive polypeptides in the canine extrahypothalamic brain and stomach. Endocrinology 105 : 14261431. 